A Moving Target -- Cognitive Narratology and Feminism

Karin Kukkonen

(University of Oslo)

\begin{abstract}
:
The present article develops a feminist approach to cognitive narratology on the basis of recent work in embodied cognition. Cognitive narratology does not traditionally consider gender perspectives, for a variety of reasons, none the least because the gendering of brains into "male" and "female" is deeply problematic. Contemporary cognitive narratology moves its point of interest however from the brain to the larger connections between brain, body and their situatedness in the world. From this new, embodied approach to cognition, we work toward a feminist dimension for cognitive narratology, drawing on issues of performativity, habitus and interpellation and highlighting the degree to which the notion of embodiment brings together both cognitive and cultural aspects of narrative. On the example of Hilary Mantel's short story 'The Assassination of Margaret Thatcher' (2014), we outline the complex ways in which narration, body images / body schemata, and metaphors interact and how these interactions can be analysed by an embodied feminist narratology that takes seriously both the embodied engagements of reading narrative and the edge within it that literature reveals.
\end{abstract}

Keywords: feminism; cognitive narratology; embodied cognition; predictive processing; Hilary Mantel

Acknowledgements: This work was supported by the Academy of Finland under grant 267599 (How the Novel Found its Feet: Embodiment and Eighteenth-Century Fiction). I would like to thank Susan Lanser and Tory Young for their excellent comments on earlier versions of this article. 
When Terry Castle reviewed the collection The Assassination of Margaret Thatcher for the New York Times (Oct 5, 2014), she stressed that author Hilary Mantel has 'assumed an esteemed place in what might be called a great tradition of modern British female storytelling', placing her next to a whole slew of names from Virginia Woolf to Zadie Smith. 'Second thought', she interrupts this seemingly obvious way of talking about Mantel. 'Despite having just done so, does one really want to organize artistic affinities by sex?' Arguably not; and she swiftly introduces a comparison with a male author before carrying on with her review of Mantel's short stories. Castle's move demonstrates the gendered logic in thinking about literary contexts and traditions of storytelling, especially when addressing a non-academic audience.

Despite having won the Booker Prize twice, Mantel still awaits discovery for literary criticism and narratology, so I can only speculate about how cognitive narratology at large would approach The Assassination of Margaret Thatcher. ${ }^{1}$ It seems fair to assume, however, that an analysis from the point of view of cognitive narratology would not concern itself with 'a great tradition of modern British female storytelling', because categories of history ('modern'), politics ('British') and gender ('female') tend to be side-lined in favour of seemingly neutral notions such as narrators, focalisers (or fictional minds), prototypical story scripts, as well as fictional worlds. Cognitive narratology draws on research in the neurosciences, social cognition and discourse psychology in order to develop models of how readers understand the fictional narratives of literary texts. Readers might construct a mental model, also called a 'storyworld', in which characters can be related to each other in the course of a narrative and which can be compared to other possible worlds or mental models. Scripts of stories or real-world experience might be deployed to make sense of narratives, and the minds and intentions of characters can be accessed through the cognitive capacity of 'theory of mind' with which we gauge the thoughts of our real-world partners in conversation, too. ${ }^{2}$ While cognitive narratology does not ignore the contributions of feminist narratology to the consideration of gender aspects in narrative perspective, emotional engagements of readers and gender-specific plot types, it rarely brings them into contact with mental models, story scripts and theory of mind, and makes no general statements on how cognitive and culturally embedded aspects of narrative, including gender, can be combined. ${ }^{3}$ Cognitive narratology, like the traditional narratology that took science as its template, pulls away from historically embedded phenomena in favour of greater generality and abstraction.

While cognitive narratology would certainly not deny that narrative pertains to the situations men and women find themselves in, respectively, in human cultures around the world, the links to cognitive processes (that interest cognitive psychology) and the build-up of the brain (that interests neuroscience) are difficult to ascertain and gender becomes a moving target seemingly outside the reach of the cognitive approach. Most scientific studies in the cognitive sciences, conducted on male, white US college students, consider cognition in gender-neutral terms. And when gender differences are observed in the cognitive work that informs this strand of narratology, they very quickly lead to the notion of an essential and holistic difference between the 'male brain' and the 'female brain' that quaintly confirms established gender stereotypes. Simon Baron-Cohen's The Essential Difference is a striking example of how a cognitive capacity, which is a priori gender-neutral, namely, theory of mind, then turns into a distinguishing feature of the 'female brain', which is gendered as empathetic and sociable. ${ }^{4}$ While Baron-Cohen's work on theory of mind has been taken up very successfully in cognitive narratology by Lisa Zunshine and others, these gender-related aspects have been largely ignored. $^{5}$ This is perhaps wise, since Baron-Cohen's notion of 'essential differences' and other cognitive and neuroscientific work assuming there is a demonstrable distinction between male and female brains are criticised by female scientists as lacking appropriate evidence and engaging in what they, fittingly, call 'neurosexism'. ${ }^{6}$ If cognitive narratology were to subscribe to the view that the male and the female brain are essentially different, it would be very hard to avoid such 'neurosexism'. If cognitive narratology, on the other hand, assumes that the brains of men and women are basically alike, then it seems that the approach would have nothing to say on gender differences at all, because these would fall out of its remit of interest and inquiry.

'Feminist narrative theory has [...] least in common with cognitive narratology,' writes Robyn Warhol in the volume Narrative Theory, where proponents of rhetorical, feminist, cognitive and 
unnatural narratology enter into debate. ${ }^{7}$ In his response at the end of the volume, David Herman, who represents cognitive narratology, suggests that the embodied, 'post-Cartesian' approach to cognition could counter Warhol's argument that cognitive narratology's 'universalism [...] overlooks the differences born of identity positions'. ${ }^{8}$ Herman leaves it at this gesture, perhaps, because the scientists and philosophers in embodied cognition whom he cites also have not considered gender perspectives in their accounts. ${ }^{9}$ It seems to me, however, that a related approach, the current perspectives on cognition as an embodied process of probability and prediction that connect easily to cultural modes of meaning-making (for short, the so-called predictive processing model), could indeed enter into a conversation with feminist narratology and feminist literary theory more generally. Predictive processing conceives of cognition across many layers as built on predictions and the way in which they are weighted with probabilities. When you reach for this special issue of Textual Practice, for example, the muscles in your hand already prepare the right grip before your fingers have even touched the cover; and, as you scan the text, your skills in reading English already allow you to predict the next couple of words through probable patterns of syntax and idioms. Embodied movement, perception, but also cultural skills like reading depend on a complex set of predictions about our environment, where surprises (or, prediction errors) lead to a revision of the predictive, probabilistic model of the world that underlies cognitive processes. ${ }^{10}$ Gender, I am going to argue, needs to be fundamentally integrated into the connections between embodiment and predictions on which the approach relies, and such an integration allows cognitive narratology a sustained perspective from which to address the moving target of gender.

\section{Sheaths of Embodiment}

The title story of Hilary Mantel's collection, 'The Assassination of Margaret Thatcher', presents the prime minister's (historic) visit to an eye clinic in Windsor in the spring of 1983 through the narration of a resident of the town who unwittingly invites a man into her flat who intends to shoot Thatcher dead. ${ }^{11}$ While the narrator and the assassin wait for Thatcher to emerge from the eye clinic, they share their views on Britain's first female prime minister. The narrator, whom readers are invited to picture as a middle-class intellectual with pretensions of open-mindedness, is eerily dispassionate about the fact that a man with a gun and murderous intentions sits in her flat or about the prospect that Thatcher is about to be shot from her living room window. The narrator and the assassin agree that Thatcher must die. It all ends with these lines from the female narrator:

High heels on the mossy path. Tippy-tap. Toddle on. She's making efforts, but getting nowhere very fast. The bag on the arm, slung like a shield. The tailored suit just as I have foreseen, the pussy-cat bow, a long loop of pearls, and -- a new touch -- big goggle glasses. Shading her, no doubt, from the trials of the afternoon. Hand extended, she is moving along the line. Now that we are here at last, there is all the time in the world. The gunman kneels, easing into position. He sees what I see, the glittering helmet of hair. He sees it shine like a gold coin in a gutter, he sees it big as the full moon. On the sill the wasp hovers, suspends itself in still air. One easy wink of the world's blind eye: 'Rejoice,' he says. 'Fucking rejoice.' (2014, 288).

The narrator adds mock-heroic touches to her description of the prime minister's attire. Her famous handbag is 'slung like a shield' and her signature 'do turns into a 'glittering helmet of hair'. In this context, even the 'tailored suit' resembles a suit of arms. In the mock-epics of the eighteenth century, the commodity culture of the modern age is ridiculed when placed against the ancient, epic model. The brocades, silks and carefully pressed locks in Alexander Pope's The Rape of the Lock (1714) present the battles over female honour fought in the eighteenth-century drawing room as encounters that gain ironic edge when juxtaposed with the conventions of the Iliad or Aeneid. Mantel's narrator considers Thatcher's insignia of power-dressing and her assumption of a male way of speaking similarly as 'ridiculous'. 'It's the fake femininity I can't stand, and the counterfeit voice' $(2014,266)$. 
Thatcher, according to Mantel's narrator, 'can’t see how ridiculous she is' (274).

But Thatcher's power-dressing comes with real power. She does not have to rely on the poet Pope to inscribe her name 'midst the stars'. And ridiculous as it might sound when she said in an actual interview, 'Of course I am obstinate in defending our liberties and our laws. That is why I carry a very large handbag', ${ }^{12}$ the obstinacy that is captured by the handbag is real and merciless. The assassin understands this. 'It's not about her handbag. It's not about her hairdo.' (275). As becomes clear in the conversation between Mantel's narrator and the assassin, he does actually not 'see what I [the narrator] see.' His view of Thatcher and her body is very different, as emerges when he mentions the hunger strikes by Bobby Sands and others in Northern Ireland in 1981 in their bid to claim status as political prisoners from Thatcher's government. 'Your body digests itself. It eats itself in despair. You wonder why she can’t laugh? I see nothing to laugh at' (276). In both the assassin and the narrator, the hatred of Margaret Thatcher is connected to the body, but the modes of embodiment which are addressed are very different.

The narrator refers almost exclusively to the way in which Thatcher dresses, presents and comports herself, that is, her "body image". The assassin, in counterdistinction, seems to focus on the way in which her body is experienced pre-consciously, that is, the "body schema" of Thatcher (and her victims). Body image and body schema refer to the ways in which embodiment connects to the cultural manipulations of movement, dress and looks and to the pre-conscious processes of muscles, neurons and brain chemistry respectively. ${ }^{13}$ Mantel draws on both these modes of embodiment and plays them off against each other. While the narrator is not physically threatened by Thatcher, as a self-described member of the intelligentsia, she is culturally threatened by her. In one of the very few instances where Mantel's narrator breaks her mock detachment from Thatcher, we read the following: 'I thought, there's not a tear in her. Not for the mother in the rain at the bus stop, or the sailor burning in the sea. She sleeps four hours a night. She lives on the fumes of whisky and the iron in the blood of her prey' (2014, 278). Underneath the surface of ridiculous power-dressing and protective 'dos, the narrator comes to understand, there is a predator. For a moment, the narrator moves away from the mock-heroic incongruence in the appearance of the prime minister and relates the assassin's perception of her as a visceral creature conceived in hyper-masculine terms. In this dialogue of embodied perspectives between the narrator and the assassin, Mantel develops a multi-layered image of sheaths of embodiment in 'The Assassination of Margaret Thatcher'.

Thatcher as predator implies a merciless creature that tears at its victims and thrives on their misery. Such an embodied literary image depends on the ingestion of the harsh substances of whisky and blood and the pre-conscious verbal senses of smell and taste which they refer to. Thatcher as a mock-heroic politician, in turn, implies a ridiculous posturing unaware of its own insufficiency. Thatcher's 'tottering' style of walking in high heels, her choice of clothing and the gestures of protection and attention which her handbag and hairdo imply make for a sharp contrast through a difference between body image and body schema connected to the perspectives of the narrator and the assassin. Both images capture the embodied nature of Thatcher, but Mantel chooses not to present the prime minister, who does not appear until the end of the short story, in terms of fixed embodiment. She captures imaginatively her way of relating to the environment and her impact on her contemporaries.

As the cognitive narratologist looks into the embodied dimension of cognition in Mantel's text, she draws out the verbs of motion with their particular embodied phenomenology (such as 'totter'), sensual perception (such as 'fumes of whisky') and descriptions of bodily constraints and freedoms (such as 'slung as a shield'). From these elements an embodied image of the character and her relationship to the environment emerges that can sometimes be tied to a particular narrative perspective, such as the Mantel's narrator. The literary text conjures a richly inhabited lifeworld that is thick with embodied experiences. ${ }^{14}$ If second-generation cognitive approaches to narrative are right, then these embodied uses of language create embodied resonances in readers which echo the 'tottering' of the mock-heroine and the perception of 'fumes' of the predator, leading readers to embody the two perspectives themselves. The predictive aspect sharpens the importance of such embodiment. One is likely to perceive different aspects as salient when Thatcher appears a mock- 
heroic politician than when she appears as a predator. A different repertoire of comportment and interaction emerges, a different way of judging these interactions (and hence forming new expectations), and eventually a different probable conclusion to the narrative plot. There is a clear connection, from such a perspective, between the bodily experience, one's thoughts or intentions about objects in the world and one's actions within that world. Mantel asks her readers to move through different layers of embodiment as her narrator and the assassin lay in wait for a glimpse of the prime minister. The two different modes of embodiment are not simply limited to the physical appearance of Thatcher. They also imply two different ways of interacting with others and affecting others' lives, and, in turn, they suggest different appropriate ways of responding to her. Within the plot of the fictional narrative, they also outline different ways for how the story is likely to end: the tottering mock-heroic politician could simply disappear into obscurity, while the predator needs to be put down.

Drawing on embodied cognition and predictive processing, I have elsewhere discussed these connections in terms of 'cascades of cognition', where the different levels feed into each other. Bodily experience and the expectations of how the physical and cultural environment responds to our actions enters a feedback loop that starts modifying each other, and that can be dramatized in the development of a literary scene or plot. ${ }^{15}$ Because of the core role of probability and prediction, this strand of cognitive narratology allows us to think of the richly inhabited lifeworld as structured along genderlines and the predictions around embodiment that can be coded as predominantly female, such as the mock-heroine, or predominantly male, such as the predator.

\section{Performance, Habitus, Interpellation}

In the framework of embodied predictive processing, cognitive narratology is not on neutral ground anymore. The necessity to discuss gender becomes even clearer, perhaps, once we turn our attention to the embodied practices that are traditionally confined to the cultural sphere but that should be considered, as I shall argue, as intimately entwined with processes of embodied cognition.

In the article 'Throwing Like a Girl', Iris Marion Young revisits Maurice Merleau-Ponty’s phenomenological account of the 'lived body' from a gender perspective and draws attention to the pre-conscious ways in which girls and women constrain their own bodily movement in accordance with gender expectations. 'The space available to our movement is constricted space,' she writes. ${ }^{16}$ In embodied cognition, the body's assessment of sensory-motor contingencies through which we relate to the world around us play a key role. Throwing a ball implies, within the muscle movement of the arms (and according to the predictive-processing account), a series of predictions on how high and far the ball is going to go, even before the projectile has reached this point in its trajectory. When we swing our arms back and forth in preparation of a throw, we adjust our muscle movements to fit to the optimal predictions once we actually release the ball. Such predictions are much more precise in expert throwers (say, for example, professional cricketers) and they develop through repeated practice and imitation. Arguably, for female throwers, who are habituated to a constrained bodily experience through female dress and ideal comportment, the predictions that inform the throw (and hence the throw itself) will be vastly different. Within the predictive processing account, female throwers are not condemned to remain constrained, however, because conscious practice can recalibrate predictions and lead to more powerful throws in female athletes. Yet the issue remains that in everyday contexts female role models provide practice and entrainment in a more constrained, female mode of movement.

The embodied experience of the world and our sense of the options to take action within it (that is, our very perception of the world in the embodied cognition account), then becomes profoundly dependent on the predictions derived from templates of male or female comportment that have been engrained for years. Culture and cognition cannot be separated once we acknowledge that embodied experience is something which does not emerge ineffably between bodies and the environment, but that, dependent on developing predictions, it is shaped by our muscle memory of movement and the feedback of our physical, social and mediated environment on our performance of 
this movement.

Predictive processing is a comparatively young strand in the cognitive sciences and philosophy of mind, and the debates, in particular with respect to the role and importance of embodiment, are ongoing. ${ }^{17}$ In what follows, I shall assume that the embodied and embedded dimension of predictive processing cannot be separated from its probabilistic dimension. To my mind, it is exactly the dialogue and feedback between embodied experience and the expectations that prefigure, shape and make it meaningful that constitutes the strength of embodied predictive processing for the analysis of cultural phenomena, such as literary narrative and it can be profitably developed in this respect in dialogue with feminist critiques of embodiment.

Simone de Beauvoir, in The Second Sex, famously writes 'One is not born, but rather becomes, a woman'. ${ }^{18}$ As Sonia Kruks points out, this phrase presents the female experience as 'situated' in a particular bodily and social context and it 'denaturalises' it at the same time. ${ }^{19}$ Femininity is a constructed category, but it nevertheless forms part of the lived experience of the female subject (also De Beauvoir draws on Merleau-Ponty), and "subjectivity is corporally constituted; it is co-extensive with the body, while being simultaneously a 'point of view'." 20 In what follows, I shall explore three different avenues for an embodied cognitive narratology from this Beauvoirean perspective, as one 'becomes' a woman through the performance of such a gender role, through the living of a particular habitus and through the interpellation of others to assume a recognisable position in intersubjective exchanges.

The term 'performance' is a difficult one with respect to the way in which embodied predictive processing plays out in everyday cognition. The permutations which the term underwent in the work of Judith Butler from Gender Trouble (1990) to Bodies That Matter (1993), for example, are indicative of the tensions between empowerment and constraints in gendered, embodied actions which are necessary, I think, to develop the full versatility of embodied cognition. While the throwing of a ball is quite clearly a performance in the sense that the potential of movement is actualised in the world in a particular style and manner, it does not necessarily mean that this performance is 'theatrical' in the sense that we assume a role, consciously and with deliberation. The performance of embodied actions can arguably be changed through conscious practice, but it usually cannot be assumed and discarded with the same ease and detachment that one associates with a theatrical role. Furthermore, the predictive, probabilistic models of embodied and social cognition, which shape our expectations, are not discursive in the sense that they can be confined to the realm of social and linguistic constructions. They are a model of the world that develops in constant interaction with physical and cultural feedback from this world. In that sense, predictive processing is anchored in the body just as much as in the cultural scripts and roles, with no notion of a separate 'discourse'. 'Performance' in this context can take a range of meanings, from deliberate, practiced and creatively appropriating to automatic, preconscious and constrained, depending on how, in each individual case, the feedback loop between embodied experience and the probabilistic predictions is configured. The state of 'becoming', in this model of embodied predictive processing, can remain in flux.

Habitus is most closely connected with the work of Pierre Bourdieu and his analysis of embodied social practices, where the entrained actions of the individual demonstrates his belonging to a particular group such as a social class or an ethnic community. Bourdieu, to my knowledge, does not discuss gender in particular, but arguably, there is a gendered dimension to the embodied practice of habitus that cuts, in intersectional fashion, across class. ${ }^{21}$ The narrator and the assassin in Mantel, for example, constantly size each other up in terms of their social class and it is the attention to detail, as in Bourdieu's analyses of habitus as social practice, that brings such larger social formations to the fore. $^{22}$ The narrator assesses the assassin as one of "those who were bright enough to say "affinity", but still wore cheap nylon coats' $(2014,273)$, that is, a working class man who was not given equal educational and professional opportunities as her own middle-class self. At the same time, the fact that she can only offer demerara sugar for his tea, marks her out as a member of the 'bourgeoisie' (272) for him. Language, dress, and food habits carry clear social markers that become invisible within one's own social class. Habitus also extends into the way in which characters shape their environment through embodied interaction. Even though the narrator realises that she has an assassin 
in her drawing room, she still feels the need to be a proper middle-class hostess, and Mantel chooses to point this out in her gestures in this world. She drags the duvet over her unmade bed 'to tidy it' (265), she prepares tea for him and is ‘flustered by a failing in hospitality' (272) when he comments on the sugar missing from his tea.

The lived habitus of the narrator includes a very embodied way of engaging with and organising her surroundings, as well as her choice of words. The character 'becomes' a woman, and more specifically a middle class woman, through both actions and language. Gender-oriented sociolinguistics (I am thinking in particular of Deborah Cameron's Verbal Hygiene [1995]) and the embodied approach in cognitive linguistics are arguably compatible from this point of view. The language that is used does not only reflect that way in which we conceptualise the world around us, it also provides the very means of conceptualisation when we think of cognition as grounded in the human body. On the one hand, it seems that a sense of bodily relations, distances and modes of movement underlie the metaphors and situated conceptualisations which we express in language, our bodies shape the way in which we express abstract thoughts in language. ${ }^{23}$ On the other hand, it seems that the embodied patterns and models of language, in particular as it is given in socio-typical language use, prefigure (as a predictive, probabilistic model) our very perception of the world and, by extension, our understanding of ourselves and our social contexts. ${ }^{24}$ And of course, language is often heavily gendered. For example, even though in 'The Assassination of Margaret Thatcher' Mantel does not specify explicitly that her narrator is female, the moment when she describes herself as 'flustered over a failing in hospitality' makes it relatively clear that the voice narrating the encounter is a woman's. The verb 'flustered' describes a state of the body and mind which is particularly gendered as female and it is part of the embodied habitus of the middle-class woman, predicting how she should feel in a particular situation and, in turn, giving conceptual shape to this particular bodily experience when it occurs.

The performance of gender roles and the lived practice of the habitus are complemented by the way in which this embodied experience of the world gains a normative dimension through Althusserian interpellation. As the narrator in Mantel's 'The Assassination of Margaret Thatcher' makes clear, Thatcher does not simply perform a gender role. Instead, her looks are perceived as an accusation of the insufficiency of other looks and a summons to imitate her (and thus become relatable by her standards). The narrator explains to the assassin,

'Mind you,' I said, 'she'd probably laugh if she were here. She'd laugh because she despises us. Look at your anorak. She despises your anorak. Look at my hair. She despises my hair.'

He glanced up. He'd not looked at me before, not to see me; I was just the tea-maker. 'The way it just hangs there,' I explained. 'Instead of being in corrugations. I ought to have it washed and set. It ought to go in graduated rollers, she knows where she is with that sort of hair.' (2014, 274)

The narrator draws attention to her performance of the female gender role and how closely it is related to others' normative expectations and demands. She is certain that Thatcher 'despises' her hair because it is not pressed and controlled by the technologies of coiffure as is her own. The narrator does not look as she feels she 'ought' to look by the standards of Margaret Thatcher and hence experiences the interpellation of 'corrugations' and 'graduated rollers'.

Mantel provides another mock-heroic moment in her short story here, as she relates Thatcher's will to dominate through her well-controlled looks and the need to 'know where she is with that sort of hair'. At the same time, however, she points to an important aspect of the embodied female experience at the point where interpellation and objectification are linked. Young in 'Throwing Like a Girl' suggests that the inhibition of female throwers is to do with the fact that they do not direct their attention to 'what they want to achieve through their bodies' but rather 'put attention on their bodies'. The female body, so Young, is 'looked at and acted upon' ${ }^{25}$ The issue of gendered body images, in other words, is not only to do with the different predictive models available to different 
genders but also with the degree to which the predictive model and its performance is regarded and assessed from a third-person perspective. The narrator sees Thatcher through her accessories, the handbag and the hairdo, because that is how she herself judges her and feels to be judged by her. The felt reliability of the feedback loop between embodied experience and predictive, probabilistic modes now comes to the fore. This is what the predictive processing approach calls 'precision' ${ }^{26}$ For Mantel's narrator, the reliability of her own body image and that of Thatcher is a problem to be considered, whereas for the assassin, it is not. It is not my intention to claim that men do not experience interpellation of this kind; I merely mean to point out how Mantel differentiates between the embodied experience of the narrator and the assassin along these lines of 'becoming' as well.

The basic assumption that mind and body work together in meaning-making has been complicated beyond the distinction of 'body image' and 'body schema' in several respects now, and we have three dimensions along which an embodied cognitive narratology can engage with questions of gender. First, the feedback loop between embodied experience and the environment can be configured in different ways, ranging from greater agency of the individual to create one's predictive models (that is, performance as theatre) to greater constraints from the predictive models on individual behaviour (that is, performance as control). By tracing how the embodied actions and perceptions (as mentioned in the narrative text) are related to these larger expectations, cognitive narratologists can reconstruct the relative balance of this feedback loop and come to an assessment of the gendered differences in characters' experiences of their body image and their options for actions in the environment of the storyworld. Second, the relation between language and action can be used to work out the gendered habitus of the characters and to assess how the storyworld is turned into a lifeworld. The traditional notion of narratological storyworld captures the relations of characters with each other and their interactions, leading to a plot. When the storyworld shifts into a lifeworld, this also allows for a reflection on how these relations and interactions are shaped by embodied habitus. Third, the way in which narration communicates the reliability of these feedback loops yields patterns of interpellation and objectification for characters, narrators and readers. In each of these dimensions, however, the embodied experience of gender-specific 'becoming' cannot be made independent of the body in an abstract realm of 'discourse' or 'construction'.

\section{The Embodied Edge}

Up until now, I have presented the predictive processing model as it applies to real-world cognitive embodied processes, in parallel with the words and actions of the characters in the text. However, Mantel's short story 'The Assassination of Margaret Thatcher' is an entirely verbal construct; a representation and not the real world. It has been argued, convincingly, I think, that reading a written text depends on the embodied resonances of readers to motion verbs, directions and the descriptions of bodily states. Readers make sense of the words on the page through the way in which they feel them in their own bodies. Reading might not be exclusively dependent on such resonances but it is profoundly embodied. ${ }^{27}$ At the same time, however, literary mimesis is one step removed from experiences and interactions in the real world through the mediation of language and writing.

This mediation in language and writing, as I have argued elsewhere, ${ }^{28}$ enables literary narrative to highlight aspects of our everyday lived bodies that remain invisible in the flow of realworld experience. In a conversation in the streets of Windsor, before the visit of the assassin, the narrator has the following exchange with a stranger about the visit from the prime minister.

She said, 'There are some strong opinions flying about.'

'Mine is a dagger,' I said, 'and it’s flying straight to her heart.' $(2014,258)$

Strictly speaking, the exchange is based on a conceptual metaphor according to which an abstract element (that is, 'opinion') is characterised by a concrete, potentially embodied activity (that is, 'flying about'). ${ }^{29}$ Such combinations are ubiquitous in everyday conversations and we usually pay no heed to their embodied dimension, even though it underpins the way in which we understand these 
expressions (if conceptual metaphor theory is right). However, in this example from Mantel, the concrete, potentially embodied activity of 'flying about' regains its embodied edge when the 'opinion' is turned into a "dagger" that is 'flying straight to her heart'. The embodied resonances of the motion verb are underlined when the projectile gains physical shape and when it is given a trajectory into the vital organs of Margaret Thatcher.

In this little exchange, Mantel brings out the embodied resonances that underlie the understanding of language by turning them into concrete objects in her storyworld and thus foregrounding the predictions that shape our embodied experience and make it relatable in its attendant language use. As literary language draws attention to the (seemingly) predictable embodied experiences of its characters and narrators, it performs the double-function of (1) showing how much we are rooted in our lived bodies and of (2) denaturalising the social and cultural scripts within which our embodied experience is inevitably situated. As Mantel's narrator places her Perrier water in the fridge, remarks on the cheap nylon jacket of the assassin and gets 'flustered' over her short-comings in hospitality, this could all be natural enough. In Mantel's short story, however, we find her playing through the embodied habitus of the middle-class woman while an assassin sits in her living room and she serves him tea. Does the narrator simply lack the capacity to assume any other kind of agency? Does Mantel make a statement about the underlying dispassionateness of playing social roles? Or does the habitus of the middle-class woman also serve as a protective shell in this encounter with an assassin? In the fictional situation, these elements of habitus gain an embodied edge, too, with the dispassionate perspective on the body images that the narrator insists on.

Throughout Mantel's 'The Assassination of Margaret Thatcher', the everyday lived experience of gendered and social realities in Windsor is heightened, be it through literalised metaphors in the discourse, be it through the mock-heroic elements in its treatment of Thatcher or be it through the incongruity of the situation with the assassin drinking tea in the middle-class living room. Literary mimesis consistently draws attention to the relationship between the embodied experience and the cultural and social templates which inform its probabilities in the feedback loop of predictive processing. It gives the immersive dimension of literary reading, intensity and, depending on embodied resonances, a defamiliarising moment. Indeed, in the dialogue cited above, the embodied edge translates into the very development of the plot, which introduces a character about to pull the trigger in the midst of these 'strong opinions flying about'. With the parallel between the dagger-like opinion of the narrator and the physical bullet of the assassin, Mantel underlines the ways in which language and bodily experience shape each other. The narrative ends just before the assassination, where the verbal embodiment is about to be translated into physical events, as Thatcher comes into view. In the novella itself, Mantel's literary language keeps them in an uneasy, provocative balance.

My brief analytical snap-shots of 'The Assassination of Margaret Thatcher' give only some examples of how an embodied cognitive narratology can approach the moving target of a feminist perspective. It depends on the embodied predictive processing model of cognition, which includes both the phenomenological notion of the lived body in its surroundings and the probabilistic notion of likely scripts and templates which inform the ways in which this lived body is played out. Neither on the side of phenomenology nor on the side of cultural templates can such embodied narratology do without the gender perspective. A feminist cognitive analyse reveals how, in 'The Assassination of Margaret Thatcher', Mantel makes an assault on pre-conceived notions of gender and class through the double dimension of embodiment and prediction.

$* * *$

Close to the end of 'The Assassination of Margaret Thatcher', Mantel speaks of a 'the door in the wall' (285). 'It is a special door and obeys no laws that govern wood or iron. No locksmith can defeat it, no bailiff kick it in; patrolling policemen pass it because it is visible only to the eye of faith' (2014, 285). Mantel's short story is such as "door in the wall”. We know that Margaret Thatcher was not assassinated in the spring of 1983, even though Mantel's narrative begins with the sentence, 'Picture 
first the street where she breathed her last' (2014, 253). Mantel takes us into a storyworld that is 'visible only to the eye of faith', and while it follows the general logic of the door in that we can pass throw its threshold from one world to another, as she says, it 'obeys no laws that govern wood or iron'. Perhaps we can extend this metaphor to develop a view for an embodied cognitive feminist narratology. The cascades of cognition involved in the embodied reading of literature do not simply reproduce the gendered realities, cognitive, embodied or otherwise, of the world around us. They do not 'obey the laws' of the real world. Rather they realise the fully potential of gendered metaphors, expectations of comportment and invisible habitus in literary language: to reflect on the experience and its underlying predictions while you live it. An embodied feminist narratology can offer a perspective on how literature enables embodied immersion in fictional worlds while carrying the potential to make readers feel the embodied edge of historical, political and gendered situatedness. 

1 - Hilary Mantel, 'The Assassination of Margaret Thatcher' in The Assassination of Margaret Thatcher (London: Fourth Estate, 2014), pp. 248-88. At the time of writing this article (09 May 2016), the MLA International Bibliography lists no more than 26 entries on Mantel's substantial oeuvre (and 11 of these entries refer not to academic articles but to book reviews and interviews). Compare this to Ian McEwan’s 416 entries, Julian Barnes's 236 entries or Martin Amis's 203 entries.

2 - For the basic references to cognitive narratology drawn on here, see David Herman, Storylogic: Problems and Possibilities of Narrative (Lincoln: University of Nebraska Press, 2002), Marie-Laure Ryan, Possible Worlds, Artificial Intelligence and Narrative (Bloomington: Indiana University Press, 1991); Monika Fludernik, Toward a 'Natural' Narratology (London: Routledge, 1996); Lisa Zunshine, Why We Read Fiction (Columbus: Ohio State University Press, 2007); Blakey Vermeule, Why Do We Care About Literary Characters (Baltimore: Johns Hopkins University Press, 2010); and Alan Palmer, Fictional Minds (Lincoln: University of Nebraska Press, 2004).

3 - See Susan Lanser, Fictions of Authority: Women Writers and Narrative Voice (Ithaca: Cornell University Press, 1992) and Robyn Warhol, Having a Good Cry Effeminate Feelings and Pop Culture Forms (Columbus: Ohio State University Press, 2003) for examples of feminist treatments of narration, emotional engagements and plot types. Hilary Dannenberg, in Coincidence and Counterfactuality: Plotting Time and Space in Narrative Fiction (Lincoln: University of Nebraska Press, 2008), is a good example of how cognitive and gender perspectives can be fruitfully combined, but this remains the exception in cognitive narratology.

4 - Simon Baron-Cohen, The Essential Difference: Forget Mars and Venus and Discover the Truth about the Opposite Sex (London: Penguin, 2004).

5 - See Lisa Zunshine, Why We Read Fiction: Theory of Mind and the Novel (Columbus: Ohio State University Press, 2008) and Getting Inside Your Head: What Cognitive Science Can Tell us About Cognitive Culture (Baltimore: Johns Hopkins University Press, 2012), as well as the contributions in Paula Leverage et al. eds. Theory of Mind and Literature (Ashland: Purdue University Press, 2014).

Kay Young, 'Sex - Text - Cortex' in Susan Lanser and Robyn Warhol, eds. Narrative Theory Unbound: Queer and Feminist Interventions (Columbus: Ohio State University Press, 2016, pp. 312-22) rightly points out the need to engage with brain science from the point of view of feminist narratology but then focuses on the critique of the approach rather than an integrated model.

6 - For the term 'neurosexism', see Robyn Bluhm, 'Beyond Neurosexism: Is It Possible to Defend the Female Brain?’ in Robyn Bluhm, Anne Jaap Jakobson and Heidi Lene Maibom, eds. Neurofeminism: Issues at the Intersection of Feminist Theory and Cognitive Science (Houndsmills, Basingstoke: Palgrave Macmillan, 2012), pp. 230-45. Further articles in this volume question recent research suggesting that male and female brains show significant differences; Giordana Grossi and Cordelia Fine, "The Role of Fetal Testosterone in the Development of the "Essential Difference" Between the Sexes: Some Essential Issues’ pp. 73-104, give a trenchant critique of Baron-Cohen’s distinctions. For a classical rebuttal of research on the 'corpus callosum' (that connects the two hemispheres and is supposedly more prominent in the female brain), see Anne Fausto-Sterling, Sexing the Body: Gender Politics and the Construction of Sexuality (New York: Basic Books, 2000), particularly ch. 5. 'Sexing the Brain: How Biologists Make a Difference'.

7 - David Herman, James Phelan, Peter J. Rabinowitz, Brian Richardson and Robyn Warhol, Narrative Theory: Core Concepts and Critical Debates (Columbus: Ohio State University Press, 2012), p. 10.

8 - Ibid. 210; for Herman’s response, see pp. 220-2.

9 - Herman mentions Andy Clark, Supersizing the Mind: Embodiment, Action and Cognitive Extension (Oxford: Oxford University Press, 2008), J.J. Gibson, An Ecological Approach to Visual Perception (Boston: Houghton-Mifflin, 1979) and Alva Noë, Action in Perception (Cambridge MA: MIT Press, 2004).

10 -- See Chris Frith, Making up the Mind: How the Brain Creates our Mental World (Oxford: Wiley-Blackwell, 2007) and Andy Clark, ‘Whatever Next? Predictive Brains, Situated Agents, and the Future of Cognitive Science’ Brain and Behavioral Sciences 36.3 (2013), pp. 181-204 for accessible introductions to predictive processing.

11 -- In what follows, references to this short story will be made in parentheses in the main text.

- Quotation ascribed to Thatcher in an article discussing the term 'handbagging'. Ollie Stone-Lee, 'I Was 
Handbagged by Margaret Thatcher’ BBC News 9 April 2013. Available online at http://www.bbc.com/news/uk-politics11518330 .

13 - See Shaun Gallagher, How the Body Shapes the Mind (Oxford: Oxford University Press, 2008) for this distinction.

$14-$ A broad range of neuropsychological and philosophical accounts of how these different levels of embodied are interconnected has emerged in recent years. See Marco Caracciolo and Karin Kukkonen, eds. Cognitive Literary Study: Second-Generation Perspectives (special issue of Style 48.3, 2014) for an overview on this literature and a series of contributions that consider how elements of literary criticism can be reconceptualised through the different dimensions of embodied cognition.

15 - Karin Kukkonen, 'Presence and Prediction: The Embodied Reader's Cascades of Cognition', Style 48.3 (2014), pp. 367-84.

16 - Iris Marion Young, 'Throwing Like a Girl: A Phenomenology of Feminine Body Comportment, Mobility and Spatiality' in The Female Body Experience: “Throwing Like a Girl” and other Essays (Oxford: Oxford University Press, 2005), p. 33.

17 - See Andy Clark: Surfing Uncertainty: Prediction, Action and the Embodied Mind (Oxford: Oxford University Press, 2016) and Jakob Hohwy, The Predictive Mind (Oxford: Oxford University Press, 2013) for two key statements in the debate. Clark sees predictive processing as irrevocably rooted in the body, while Hohwy conceptualises the predictive dimension as separable from embodied experience.

18 - Simone de Beauvoir, The Second Sex (Harmondsworth: Penguin, 1983 [1949]), p. 295.

19 - See Sonia Kruks, ‘Gender and Subjectivity: Simone de Beauvoir and Contemporary Feminism’ Signs: Journal of Women in Culture and Society 18.1 (1992), pp. 89-110.

$20-$ Kruks, ‘Gender and Subjectivity’, p.107.

21 - See Toril Moi, 'Appropriating Bourdieu: Feminist Theory and Pierre Bourdieu’s Sociology of Culture', New Literary History 22.4 (1991), pp. 1019-49 for an argument introducing Bourdieu in feminist studies.

22 - See especially, Pierre Bourdieu, Practical Reason: On the Theory of Action (Cambridge: Polity, 1998) and Pierre Bourdieu, Outline of a Theory of Praxis (Cambridge: Cambridge University Press, 1977).

23 - See for example Raymond Gibbs, Embodiment and Cognitive Science (Cambridge: Cambridge University Press, 2005) and Lawrence Barsalou, 'Grounded Cognition', Annual Review of Psychology 59 (2008), pp. 617-45.

24 - See Benjamin Bergen, Louder than Words: The New Science of How the Mind Makes Meaning (Washington: Basic Books, 2012) for a popularised, comprehensive introduction to this approach. Gary Lupyan and Andy Clark, "Words and the World: Predictive Coding and the Language-Perception-Cognition Interface" Current Directions in Psychological Science 24.4 (2015), pp. 279-84 provide an up-to-date predictive processing perspective on these issues.

- Young, 'Throwing like a Girl', p. 39.

- Kukkonen, 'Presence and Prediction', p. 375.

27 - See Bergen, Louder than Words, for an outline of such embodied reading. The notion that readers experience an embodied resonance of what they read about is at the core of cognitive approaches to literature that depend on embodied cognition, such as Guillemette Bolens, The Style of Gestures: Embodiment and Literary Narrative (Baltimore: Johns Hopkins, 2012) and Marco Caracciolo, The Experientiality of Narrative: An Enactivist Approach (Berlin: DeGruyter, 2014). 
Garrett, eds. The Embodied Mind in Culture (London: Palgrave Macmillan, 2016), pp. 153-66.

29 - See George Lakoff and Mark Johnson, Metaphors We Live By (Chicago: University of Chicago Press, 1980) for the classical account on conceptual metaphors. This is a specific case of the more general point about embodiment and language I made in the discussion of habitus in the previous section. 